\title{
PENGARUH MOTIVASI, SELF EFFICACY, DAN KOMITMEN KARYAWAN TERHADAP KINERJA PERAWAT DI RUMAH SAKIT HERMINA DEPOK
}

\author{
Nurianna Harianja, Rokiah Kusumapraja, CSP Wekadigunawan \\ Universitas Esa Unggul Jakarta, Indonesia \\ Email: nurianaharianja@gmail.com,rokiah.kusumapradja@esaunggul.ac.id, \\ gunawan@esaunggul.ac.id
}

\begin{tabular}{ll}
\hline INFO ARTIKEL & ABSTRAK \\
\hline Diterima & Kinerja karyawan merupakan salah satu faktor yang memegang peranan \\
5 Januari 2022 & penting dalam mencapai tujuan perusahaan dan tujuan individu. Kinerja \\
Direvisi & adalah suatu kemampuan yang dimiliki seseorang untuk menyelesaikan \\
15 Januari 2022 & tugas yang diberikan oleh atasan sehingga diselesaikan dengan \\
Disetujui & kemampuan, kemauan dan keterampilan seseorang. Tinggi rendahnya \\
25 Januari 2022 & kinerja seorang pegawai ditentukan oleh faktor-faktor yang \\
\hline Kata Kunci: & mempengaruhinya secara langsung maupun tidak langsung. Penelitian \\
motivasi; & ini bertujuan untuk menguji pengaruh motivasi, efikasi diri, dan \\
kemanjuran diri; & komitmen karyawan terhadap kinerja perawat di RS Hermina Depok. \\
komitmen & Data yang digunakan adalah hasil penyebaran kuesioner secara langsung \\
karyawan; kinerja & pada bulan September sampai November 2020 di RS Hermina Depok. \\
perawat & Teknik pengambilan sampel menggunakan proportional systematic \\
& sampling dimana terdapat 200 sampel dari dua status kepegawaian yang \\
& berbeda yaitu pegawai tetap dan kontrak. Ada empat variabel dalam \\
& penelitian ini, yaitu motivasi, efikasi diri, serta komitmen dan kinerja \\
& karyawan. Instrumen penelitian menggunakan angket dan diukur \\
& menggunakan skala likert. Data dianalisis menggunakan Structural \\
& Equation Model (SEM). Hasil penelitian menunjukkan bahwa motivasi, \\
& efikasi diri, dan komitmen karyawan berpengaruh positif dan signifikan \\
& terhadap kinerja perawat, baik secara parsial maupun simultan
\end{tabular}

\section{ABSTRACT}

Employee performance is one of the factors that play an important role in achieving company goals and individual goals. Performance is an ability that a person has to complete a task given by superiors so that it is completed with one's abilities, willpower and skills. The high low performance of an employee is determined by factors that affect him directly or indirectly. This research aims to test the influence of motivation, self-efficacy, and employee commitment to the performance of nurses at Hermina Depok Hospital. The data used is the result of the spread of questionnaires directly from September to November 2020 at Hermina Depok Hospital.The sampling technique uses proportional systematic sampling where there are 200 samples from two different staffing statuses, namely permanent employees and contracts. There are four variables in this study, namely motivation, self-efficacy, and employee commitment and performance. The research instrument uses a Keywords: $\quad$ questionnaire and is measured using the likert scale. The data is motivation; self analyzed using the Structural Equation Model (SEM). The results

$\begin{array}{lll}\text { How to cite: } & \text { Harianja. N. et.al (2022) Pengaruh Motivasi, Self Efficacy, dan Komitmen Karyawan terhadap } \\ & \text { Kinerja Perawat di Rumah Sakit Hermina Depok. Jurnal Health Sains 3(1). } \\ & \text { https://doi.org/10.46799/jhs.v3i1.398 } & \\ \text { E-ISSN: } & \text { 2723-6927 } \\ \text { Published by: } & \text { Ridwan Institute }\end{array}$




\begin{tabular}{ll}
\hline efficacy; employee & $\begin{array}{l}\text { showed that employee motivation, self-efficacy, and commitment had a } \\
\text { commitment; nurse } \\
\text { positive and significant effect on the performance of nurses, both } \\
\text { partially and simultaneously. }\end{array}$
\end{tabular}

\section{Pendahuluan}

Kinerja merupakan salah satu faktor yang mempengaruhi keberhasilan suatu perusahaan Menurut (Kasmir, s.e., 2016) Kinerja adalah hasil kerja dan perilaku kerja yang telah dicapai dalam menyelesaikan tugas-tugas dan tanggung jawab yang diberikan dalam suatu periode tertentu. Sedangkan pengertian kinerja menurut (Hamali \& Saboor, 2019) adalah hasil pekerjaan yang mempunyai hubungan kuat dengan tujuan strategis organisasi ,kepuasan konsumen dan memberikan kontribusi ekonomi. Telah banyak dilakukan penelitian mengenai kinerja karyawan pada berbagai perusahaan, dinas, hotel, dan lainnya (Riyanto et al., 2017), (Wicaksono, 2017), (Jayaweera, 2015). Kinerja perawat dipengaruhi beberapa faktor yaitu kemampuan dan keahlian, pengetahuan, rancangan kerja, kepribadian, motivasi, kepemimpinan, kepuasan kerja, loyalitas komitmen dan disiplin kerja (Kasmir, 2016). Beberapa faktor di atas perlu diperhatikan untuk mengembangkan perawat agar memiliki kinerja yang baik. Dalam mendapatkan kinerja yang baik dipengaruhi oleh motivasi, self efficacy, dan komitmen karyawan. Sumber daya manusia berperan penting dalam menjalankan kegiatan pada suatu perusahaan, agar tujuan perusahaan dapat tercapai maka dibutuhkan karyawan yang bekerja secara efisien dan efektif sehingga memberikan hasil kerja yang baik.Karyawan memerlukan motivasi untuk bekerja lebih rajin. Selain motivasi hal ini yang dapat dipengaruhi kinerja adalah kemampuan, dengan memiliki kemampuan yang sesuai maka seorang karyawan tersebut dapat bekerja baik (M. Robbins et al., 2009). menyatakan bahwa kemampuan (ability) merupakan kapasitas seorang individu untuk melakukan beragam tugas dalam suatu pekerjaan.

Komitmen karyawan dapat dibentuk dalam organisasi perusahaan agar memiliki tujuan yang sama. Menurut Bagraim (Mahmud et al., 2010), menyatakan bahwa komitmen dapat berkembang apabila pegawai mampu menemukan harapannya dan memenuhi kebutuhannya dalam sebuah organisasi. Ketika memiliki kesetiaan dan tujuan yang sama maka hal ini akan mempengaruhi bagaimana karyawan bekerja. Hubungan antara perusahaan dan karyawan sangat berpengaruh terhadap kinerja. Semakin positif iklim organisasi maka semakin tinggi komitmen karyawan, begitu juga apabila semakin negatif iklim organisasi maka semakin rendah pula komitmen karyawan. (Sumarni \& Pramuntadi, 2019). Perlunya perhatian khusus bagi rumah sakit untuk memiliki iklim organisasi yang baik agar tercipta kinerja yang terbaik untuk kemajuan rumah sakit. Selain itu, untuk meningkatkan kinerja perawat perlu adanya self efficacy.

Dalam menjalankan pekerjaannya, perawat perlu memahami dan meyakini kemampuannya dalam menyelesaikan suatu perkejaan. Self efficacy merupakan penilaian individu terhadap kemampuan atau kompetensinya untuk melakukan suatu tugas, mencapai suatu tujuan dan menghasilkan sesuatu (Bandura, 1997). Self efficacy menentukan bagaimana perawat dapat menyelesaikan tugasnya. Semakin tinggi atau rendahnya self efficacy akan berpengaruhi kinerja perawat. Bila perawat memiliki self efficacy rendah cenderung akan menghindari tugas dan kurang mampu memberikan hasil yang baik dalam tugas yang dikerjakan. Hal ini, akan mengganggu kinerja perawat serta iklim kerja rumah sakit yang akan menjadi terhambat mencapai tujuan. Selain, Self 
efficacy, motivasi perawat dalam bekerja juga mempengaruhi kinerjanya.

Dorongan atau motivasi dalam bekerja sangat penting untuk memulai dan menyelesaikan sebuah pekerjaan. Motivasi merupakan suatu kesediaan untuk mengeluarkan tingkat upaya yang tinggi untuk tujuan organisasi yang dikondisikan oleh kemampuan upaya itu untuk memenuhi beberapa kebutuhan individual (R. J. Robbins, 2003). Dalam rangka mencapai tujuan, rumah sakit perlu memperhatikan perawat untuk meningkatkan motivasi dalam bekerja dengan memberikan reward dan lingkungan kerja yang nyaman. Apabila hal ini diabaikan maka kinerja perawat akan menurun dan akan menghambat tujuan rumah sakit dalam memberikan pelayanan kesehatan yang berkualitas. Hal ini menjelaskan bahwa motivasi dapat berpengaruh terhadap kinerja perawat sebagai karyawan rumah sakit. Kinerja perawat yang mengalami pengaruh dari komitmen karyawan, self efficacy dan motivasi terjadi di RS Hermina Depok.

Berdasarkan pengamatan yang peneliti lakukan terkait kinerja perawat, motivasi, self efficacy menjadi faktor yang berpengaruh pada keberhasilan kinerja yang perawat lakukan, terlihat dari mereka tidak memandang tugas sebagai suatu ancaman yang harus mereka hindari, perawat-perawat RS Hermina Depok banyak tergabung dalam Kelompok Staf Perawat Fungsional (KSPF). Selain itu banyak Perawat juga cenderung belum antusias dalam melakukan kenaikan jenjang perawat klinis ditunjukan dengan adanya perawat-perawat yang terlambat dalam melakukan pemberkasan untuk proses kredensial atau belum melakukan rekredensial, alasan yang muncul dikarenakan perawat menganggap kenaikan jenjang karier tersebut belum berimplikasi siknifikan terhadap kenaikan upah atau gaji. Timbul pertanyaan mengapa angka turnover perawat tinggi, apakah terdapat faktor pemicu seperti motivasi, self efficacy yang bersumber dari diri karyawan tersebut yang menjadi penyebabnya atau faktor lain seperti pengembangan karier yang karyawan rasakan atau terima selama bekerja. Berdasarkan penjelasan tersebut peneliti tertarik melakukan penelitian dengan judul "Pengaruh Motivasi self efficacy dan Komitmen Karyawan terhadap kinerja Perawat di Rumah Sakit Hermina Depok".

\section{Metode Penelitian}

Desain penelitian ini ialah untuk mencari hubungan kausal secara eksplanatori, yaitu menjelaskan letak variabel yang diteliti dan hubungan antara satu variabel dengan variabel lainnya. Pendekatan yang dilakukan dalam kajian ini adalah metode penelitian yang dilakukan dengan menjalankan pengumpulan data tentang fenomena yang ada pada subjek penelitian dan untuk meneliti sistem informasi yang berkaitan dengan fakta. Berdasarkan hipotesis desain kajian ini, banyaknya variabel yang digunakan dalam kajian yang teridentifikasi. Terdapat empat variabel yang ditelusuri yakni Kinerja Perawat, Motivasi Self Efficacy, dan Komitmen Karyawan.

Dari penjabaran teori dan hubungan antar variabel yang telah dikemukakan di atas, maka dapat dikembangkan model penelitian antara Motivasi self efficacy, dan Komitmen Karyawan terhadap kinerja Perawat.

Teknik Pengambilan sampel yang digunakan pada penelitian ini adalah Proportional Systimetic Sampling. kuesioner yang akan diuji berjumlah 36 item, yang dikelompokkan ke dalam 4 (empat) variabel, yaitu motivasi, self efficacy, kinerja perawat dan komitmen karyawan. Jumlah sampel dalam penelitian ini adalah 200 responden yang merupakan seluruh perawat yang bertugas di Rumah Sakit Hermina Depok dengan status kepegawaian Tetap dan Kontrak. 
Metode analisis yang dipergunakan dalam menganalisis data adalah SEM (Structural Equation Model). Menurut (Ghozali, 2018) teknik analisis multivariat pada penggunaan oleh peneliti untuk mengukur komplekstas keterhubungan

\section{Hasil dan Pembahasan}

Berdasarkan sebaran data karakterristik usia respondenyang berjumlah 200 responden,didapatkan jumlah sebaran data karakteristik responden yang berusia 20-30 tahun berjumlah 83 responden $(41,5 \%)$ yang berusia 31-40 tahun berjumlah 53 responden (26.5\%) yang berusia 41-50 tahun berjumlah 64 responden (32\%). Dengan kata lain perawat yang memberikan pelayanan di Rumah Sakit Hermina Depok paling banyak adalah perawat berumur 20-30. Berdasarkan sebaran data karakteristik jenis kelamin responden tersebut di dapatkan jumlah sebaran data karakteristik responden tersebut didapatkan jumlah sebaran data karakteristik responden yang berjenis kelamin laki-laji berjumlah 53 perawat $(26,5 \%)$ dan responden perempuan berjumlah 147 perawat $(73,5)$. Berdasarkan sebaran data karakteristik tingkat Pendidikan terakhir responden,diperoleh gambaran tentang tingkat Pendidikan terakhir responden yang paling dominan untuk memberikan pelayanan di Rumah Sakit Hermina Depok adalah responden dengan tingkat Pendidikan terakhir DIII Keperawatan yang berjumlah 109 perawat $(54,5 \%)$ kemudian dilanjutkan dengan tingkat Pendidikan terakhir responden S I Keperawatan yang berjumlah 6 perawat (3\%),dan yang paling sedikit tingkat variable, dalam segi rekursif maupun nonrekursif, sehingga diperoleh deskripsi penuh dan utuh dari model seutuhnya. Hasil telusuran kemudian diinterpretasikan, langkah akhir diselesaikan dan rekomendasi dibuat.

Pendidikan S2 1 perawat (0,5\%). Berdasarkan sebaran data karakteristik responden ,diperoleh gambaran tentang lama bekerja responden yang paling banyak berusia 1-5 tahun 73 perawat $(36,5 \%)$, kemudian dilanjutkan dengan lama bekerja 6-10 tahun berjumlah 35 perawat $(17,5)$, kemudian dilanjutkan dengan lama bekerja 11-15 tahun 29 perawat (14,5\%),kemudian dilanjutkan dengan lama bekerja lebih dari 15 tahun 63 perawat $(31,5 \%)$.

Validitas setiap pertanyaan akan ditentukan berdasarkan perbandingan koefisien pearson yang diperoleh (r-hitung) dan koefisien pada tabel (r-tabel). Nilai rhitung yang dominan besar dibandingkan nilai r-tabel menunjukkan bahwa penelusaran tersebut valid (Triana \& Widyarto, 2013).

Pengujian realiable ini juga penting diutilisasi untuk memastikan bahwa antar pernyataan secara konsisten dapat mengukur hal yang sama dengan hasil yang sama pada semua responden (Indrawan \& Yaniawati, 2016). Indrawan \& Yaniawati (2016) menambahkan bahwa reliabilitas instrumen dapat ditentukan oleh nilai Cronbach's Alpha. Jika nilai per item pertanyaan di atas 0,6 sehingga pertanyaan dimaksud termasuk sesuai penuh. Tabel 1 di bawah ini menunjukkan hasil uji validitas dan reliabilitas data.

Tabel 1

Hasil Uji Validitas dan Reliabilitas

\begin{tabular}{|c|c|c|c|c|}
\hline Variabel & Item & r-hitung $\left.{ }^{*}\right)$ & Cronbach's Alpha & Keterangan \\
\hline \multirow{5}{*}{$\begin{array}{c}\text { Kinerja Perawat } \\
\text { (Y) }\end{array}$} & Y-1 & 0,815 & \multirow{5}{*}{0,890} & \multirow{5}{*}{ Valid \& Reliabel } \\
\hline & Y-2 & 0,691 & & \\
\hline & $\mathrm{Y}-3$ & 0,834 & & \\
\hline & $\mathrm{Y}-4$ & 0,830 & & \\
\hline & Y-5 & 0.579 & & \\
\hline
\end{tabular}


Pengaruh Motivasi, Self Efficacy, dan Komitmen Karyawan terhadap Kinerja Perawat di Rumah Sakit Hermina Depok

\begin{tabular}{|c|c|c|c|c|}
\hline Variabel & Item & r-hitung $\left.{ }^{*}\right)$ & Cronbach's Alpha & Keterangan \\
\hline & Y-6 & 0,809 & & \\
\hline & Y-7 & 0,846 & & \\
\hline & Y-8 & 0,650 & & \\
\hline & Y-9 & 0,722 & & \\
\hline & Y-10 & 0,815 & & \\
\hline & Y-11 & 0,882 & & \\
\hline & $\mathrm{Y}-12$ & 0,774 & & \\
\hline & Y-13 & 0,782 & & \\
\hline & Y-14 & 0,860 & & \\
\hline & Y-15 & 0,846 & & \\
\hline & Y-16 & 0,848 & & \\
\hline & Y-17 & 0,774 & & \\
\hline & Y-18 & 0,694 & & \\
\hline \multirow{6}{*}{ Motivasi (X1) } & $\mathrm{X} 1-1$ & 0,804 & \multirow{6}{*}{0,894} & \multirow{6}{*}{ Valid \& Reliabel } \\
\hline & $\mathrm{X} 1-2$ & 0,833 & & \\
\hline & $\mathrm{X} 1-3$ & 0,777 & & \\
\hline & $\mathrm{X} 1-4$ & 0,764 & & \\
\hline & $\mathrm{X} 1-5$ & 0,799 & & \\
\hline & $\mathrm{X} 1-6$ & 0,844 & & \\
\hline \multirow{6}{*}{ Self Efficacy (X2) } & $\mathrm{X} 2-1$ & 0,871 & \multirow{6}{*}{0,913} & \multirow{6}{*}{ Valid \& Reliabel } \\
\hline & $\mathrm{X} 2-2$ & 0,839 & & \\
\hline & $\mathrm{X} 2-3$ & 0,872 & & \\
\hline & $\mathrm{X} 2-4$ & 0,667 & & \\
\hline & $\mathrm{X} 2-5$ & 0,757 & & \\
\hline & $\mathrm{X} 2-6$ & 0,844 & & \\
\hline \multirow{6}{*}{$\begin{array}{c}\text { Komitmen } \\
\text { Karyawan (Z) }\end{array}$} & Z-1 & 0,870 & \multirow{6}{*}{0,963} & \multirow{6}{*}{ Valid \& Reliabel } \\
\hline & $\mathrm{Z}-2$ & 0,866 & & \\
\hline & Z-3 & 0,808 & & \\
\hline & Z-4 & 0,744 & & \\
\hline & $\mathrm{Z}-5$ & 0,858 & & \\
\hline & Z-6 & 0,870 & & \\
\hline
\end{tabular}

*) Nilai r-tabel $=0,361$

Sumber: Data diolah peneliti (2021)

Berdasarkan ketentuan uji validitas dan reliabilitas yang telah disebutkan sebelumnya, Tabel 1 menunjukkan bahwa semua item pertanyaan, yaitu Kinerja Perawat (18 item), Motivasi (6 item), Self Efficacy (6 item), dan Komitmen Karyawan (6 item) dinyatakan valid dan reliabel. Setiap item pertanyaan dapat digunakan untuk mengumpulkan data dan seluruh data yang diperoleh selanjutnya akan diuji untuk mengetahui kelayakan model dan membuktikan hipotesis yang telah ditetapkan.

A. Structural Equation Model

Pengujian ini dilakukan untuk mengetahui kelayakan model (dengan analisis Goodness of Fit) dan uji hipotesis (dengan fungsi Bootstrapping), semua pengujian dilakukan menggunakan Structural Equation Model (SEM). 


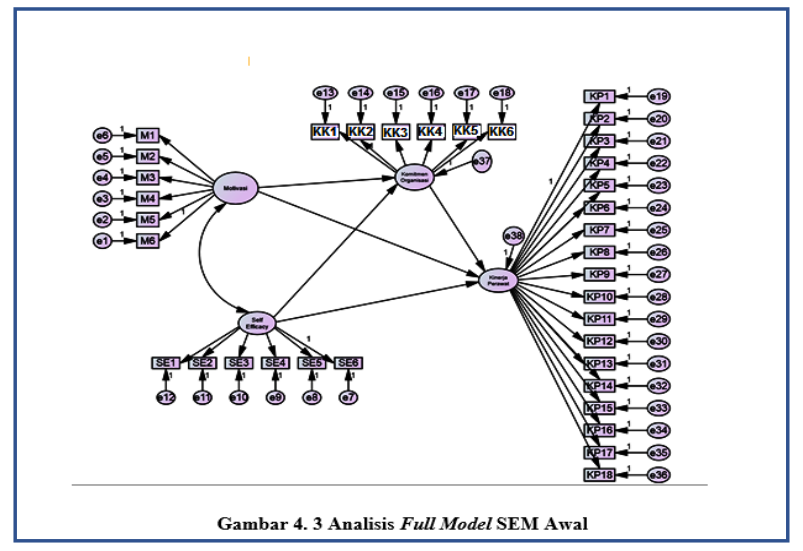

B. Three-Box Method

Analisis indeks jawaban per variabel ini bertujuan mengetahui gambaran deskriptif mengenai jawaban atas item-item pertanyaan yang diajukan pada responden. Skor tertinggi adalah 5 dan terendah adalah 1 dengan total responden 200 orang. Nilai skor rata-rata (indeks) yang dikategorikan ke dalam rentang skor berdasarkan perhitungan three box method (Ferdinand, 2008).
Batas atas rentang skor : $\left(\% \mathrm{~F}^{*} 5\right) / 5=$ $(200 * 5) / 5=200$

Batas bawah rentang skor : $\left(\% \mathrm{~F}^{*} 1\right) / 5$ $=(200 * 1) / 5=40$

Berdasarkan perhitungan di atas maka dihasilkan skor antara $40-200$ dengan rentang sebesar 160. Hasil rentang tersebut dibagi tiga (three box method), yaitu sebesar 53 sehingga menghasilkan pembagian sebagai berikut:

Tabel 2

Three Box Method

\begin{tabular}{cc}
\hline $40-93$ & Rendah \\
\hline $94-146$ & Sedang \\
\hline $147-200$ & Tinggi \\
\hline
\end{tabular}

Tabel 3

Matriks Tanggapan Responden Rumah Sakit Hermina Kota Depok

\begin{tabular}{llcccc}
\hline \multirow{2}{*}{ No } & Variable & \multicolumn{4}{c}{ Posisi Tanggapan Responden } \\
\cline { 3 - 6 } & & Rendah & Sedang & Tinggi & Perilaku \\
\hline 1 & Kinerja Perawat $(\mathrm{Y})$ & - & - & V & Tinggi \\
\hline 2 & Motivasi $\left(\mathrm{X}_{1}\right)$ & - & - & V & Tinggi \\
\hline 3 & Self Effacy $\left(\mathrm{X}_{2)}\right.$ & - & - & V & Tinggi \\
\hline 4 & Komitmen Karyawan $(\mathrm{Z})$ & - & - & V & Tinggi \\
\hline
\end{tabular}

Berdasarkan Tabel 3 di atas memperlihatkan respon responden dalam penelitian ini terhadap Kinerja Perawat, Motivasi, Self Efficacy, dan Komitmen Karyawan di Rumah Sakit Hermina Depok. Hasil penelitian menunjukan bahwa seluruh variabel memiliki respon yang bernilai positif secara keseluruhan. Analisis deskriptif dengan menggunakan pendekatan three box method di mana variabel Kinerja Perawat, Motivasi, dan Self Efficacy, serta Komitmen Karyawan masuk dalam kategori tinggi.

C. Uji Goodness of Fit

Pengujian kelayakan model sebelumnya memberikan rekomendasi untuk dilakukan modification indices yang bertujuan untuk mendapatkan hasil dengan 
Goodness of Fit yang lebih baik. Gambar

Goodness of Fit setelah dimodifikasi:

1 di bawah ini menunjukkan hasil uji

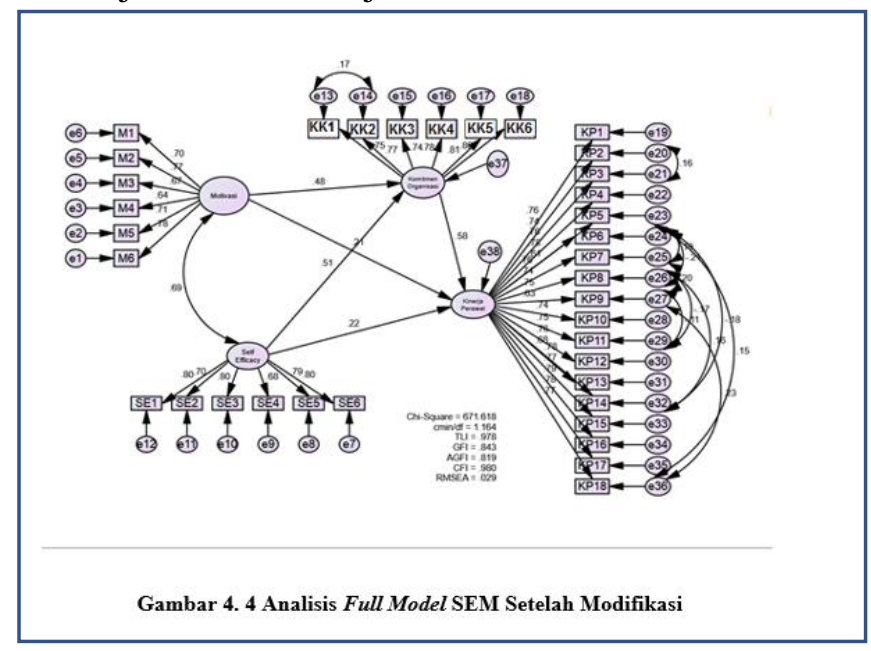

Berdasarkan pengujian yang dilakukan, diperoleh nilai pada beberapa indeks yang akan menentukan kelayakan model penelitian. Nilai CMIN/DF yang diperoleh yaitu sebesar 1,164, maka dapat dinyatakan bahwa model penelitian termasuk dalam kategori goodness of fit. Nilai GFI, yaitu sebesar 0,843 , juga merupakan indeks yang menunjukkan bahwa model penelitian merupakan model yang fit. Selanjutnya, skor TLI sebesar 0,978, CFI sebesar 0,980, dan RMSEA sebesar 0,029 juga mengindikasikan bahwa model yang digunakan telah fit dan layak.

Nilai chi-square yang diperoleh pada model dapat digunakan untuk mengevaluasi outlier multivariat melalui perbandingan dengan nilai mahalanobis distance pada probabilitas $\mathrm{p}<0,001$. Apabila nilai chi-square lebih kecil dibandingkan nilai mahalanobis distance, berarti data yang terkumpul memiliki outlier multivariat. Pada model, nilai chisquare yang diperoleh pada tingkat signifikansi 0,004 adalah 671.618 dan hasil uji outliers menunjukkan bahwa nilai tertinggi dari semua data terletak pada observasi ke 64, yaitu sebesar 115.601, dimana nilai ini masih berada di bawah nilai chi-square. Dengan demikian, tidak terdapat adanya outlier multivariat pada data, sehingga keseluruhan data dapat digunakan untuk kebutuhan analisis penelitian.

Selain kelayakan model, uji normalitas data juga penting dilakukan, yaitu melalui p-plot dan Kolmogorov Smirnov test yang disajikan pada Gambar 2. Berdasarkan gambar, model penelitian teleh memenuhi asumsi normalitas titiktitik yang terlihat pada p-plot mengikuti dan mendekati garis diagonal. Normalitas data juga dibuktikan dengan nilai signifikansi pada Kolmogorov Smirnov test yang lebih besar daripada 0,050 (pvalue $=0,200$ ) Dengan demikian, semua data dapat dianalisis lebih lanjut karena telah terdistribusi normal.

\section{Pengujian Hipotesis}

Uji ini dilakukan untuk mengetahui pengaruh langsung secara parsial dan simultan. Analisis pengaruh langsung secara parsial ditentukan berdasarkan p-value dan Critical Ratio (CR). Apabila CR yang lebih besar atau sama dengan 1,967 dan p-value kurang dari 0,05 , maka hipotesis alternatif atau hipotesis penelitian akan diterima. Standardized Regression Weight (SRW) juga 
penting untuk diketahui karena nilainya dapat menunjukkan besarnya pengaruh antar variabel. Selain p-value, analisis secara simultan juga ditentukan berdasarkan p-value dan nilai R-square (R2) untuk mengetahui persentase besarnya pengaruh variabel bebas dan/atau mediasi terhadap variabel terikat. Tabel 2 di bawah ini menunjukkan hasil uji hipotesis pada pengaruh secara langsung.

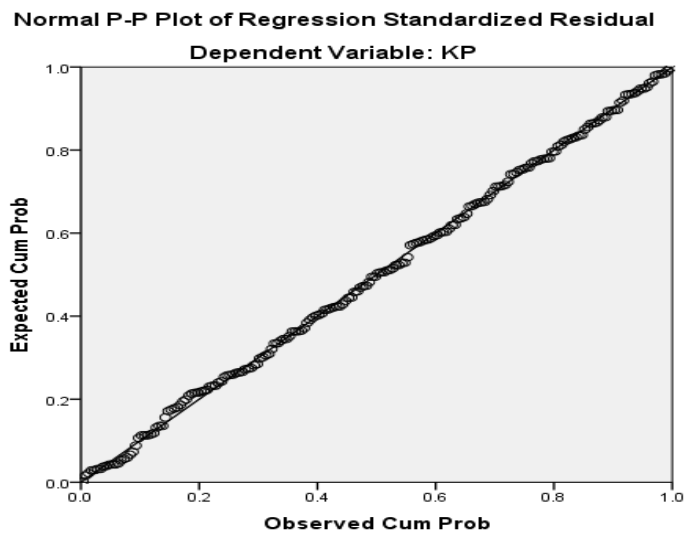

Gambar 2

Hasil Uji Normalitas

Tabel 2

Uji Hipotesis

\begin{tabular}{ccccc}
\hline Hipotesis & CR & SRW & p-value & Hipotesis Penelitian \\
\hline Komitmen Karyawan $\rightarrow$ Kinerja & 4,944 & 0,576 & 0,000 & Diterima \\
Perawat & 2,754 & 0,208 & 0,006 & Diterima \\
Motivasi $\rightarrow$ Kinerja Perawat & 2,918 & 0,222 & 0,004 & Diterima \\
Self Efficacy $\rightarrow$ Kinerja Perawat & 5,948 & 0,475 & 0,000 & Diterima \\
Motivasi $\rightarrow$ Komitmen Karyawan & 6,370 & 0,508 & 0,000 & Diterima \\
Self Efficacy $\rightarrow$ Komitmen Karyawan & \multicolumn{5}{c}{ Simultan } \\
\hline Hipotesis & R-Square & p-value & Hipotesis Penelitian \\
\hline Motivasi, Self Efficacy, Komitmen & 0,817 & 0,000 & Diterima \\
Karyawan $\rightarrow$ Kinerja Perawat & \multicolumn{5}{c}{} \\
\hline
\end{tabular}

\section{Pengaruh Komitmen Karyawan Terhadap} Kinerja Perawat

(Sinambela, 2012) menyebutkan

bahwa komitmen Karyawan yang tinggi diperlukan untuk menciptakan iklim kerja yang profesional, dan kemudian akan berdampak baik terhadap hasil kerja karyawannya. Tabel 2 menunjukkan bahwa kinerja perawat RS Hermina Depok secara signifikan dan positif dipengaruhi oleh komitmen Karyawan $(\mathrm{p}$-value $=0,000 ; \mathrm{CR}=$ 4,944), dengan pengaruh sebesar 0,576. Dengan demikian, meningkatnya komitmen
RS Hermina Depok dalam mendukung komitmen terbukti berdampak positif pada meningkatnya kinerja perawat. Penelitian Azizah \& Gustomo (2015); Gruman \& Saks (2011); Ilyas \& Nurtjahjanti (2015); Mardyana \& Riana (2019); dan Nurfajar et al. (2018) memberikan hasil yang senada, bahwa komitmen karyawan terhadap perusahaan akan berpengaruh secara positif dan signifikan terhadap kinerjanya.

Menurut Ilyas \& Nurtjahjanti (2015), pegawai atau karyawan yang melakukan pekerjaan dengan komitmen, kemungkinan 
dapat mengembangkan potensi diri, pengalaman dan kualitas kerja yang mengarah pada meningkatnya produktivitas secara individual. (Gruman \& Saks, 2011) menambahkan, peningkatan Komitmen Karyawan yang berperan dalam meningkatkan kinerja karyawan berkaitan dengan bagaimana suatu perusahaan menciptakan kenyamanan pada lingkungan kerja sehingga karyawan merasa terikat dan nyaman dengan lingkungan tersebut, dengan demikian para karyawan akan mengupayakan untuk bekerja dengan totalitas dan loyalitas.

\section{Pengaruh Motivasi Terhadap Kinerja Perawat}

Tabel 2 menunjukkan bahwa kinerja perawat RS Hermina Depok dipengaruhi oleh motivasi secara positif dan signifikan ( $\mathrm{p}$ value $=0,006 ; \mathrm{CR}=2,754)$, dengan pengaruh sebesar 0,208. Dengan demikian, dapat ditarik kesimpulan jika motivasi kerja para perawat di RS Hermina Depok ditingkatkan, maka kinerja perawat tersebut juga akan meningkat secara signifikan. Astuti \& Lesmana (2018); Salawangi et al. (2018); dan Zainaro et al. (2017) mendukung hasil ini dengan menunjukkan bahwa kinerja perawat berhubungan secara signifikan dengan motivasi kerjanya.

Motivasi dinilai sangat diperlukan agar karyawan lebih bersemangat dan senantiasa menunjukkan responsibilitas dalam bekerja untuk menghasilkan hasil kerja terbaik. Kasmir (2016) membenarkan, bahwa motivasi kerja adalah faktor yang mempengaruhi kinerja, karyawan akan berupaya menyelesaikan pekerjaan atau karya dengan baik jika dirinya merasa didukung, baik secara instrinsik maupun ekstrinsik. Hal ini berkaitan dengan kepercayaan diri yang terbangun oleh dorongan yang diterima oleh karyawan, sebagaimana disebutkan oleh Ardi et al. (2017) bahwa motivasi, dorongan, arahan, dan bimbingan kepada para karyawan dapat meningkatkan rasa percaya diri sehingga karyawan memiliki keyakinan yang lebih besar terhadap kemampuannya.

\section{Pengaruh Self Efficacy Terhadap Kinerja Perawat}

Self-efficacy atau efikasi diri merupakan bentuk keyakinan seseorang pada kemampuannya dalam melaksanakan tugas atau pekerjaan (Ardi et al., 2017). Hasil uji hipotesis menunjukkan adanya pengaruh self efficacy secara signifikan dan positif terhadap kinerja perawat RS Hermina Depok (p-value $=0,004 ; \quad \mathrm{CR}=2,918)$, dengan pengaruh sebesar 0,222. Hasil ini memberikan simpulan bahwa dengan meningkatkan self efficacy perawat RS Hermina Depok, maka kinerja perawat juga akan meningkat secara signifikan. Penelitian Kakui \& Gachunga (2016) mendukung hasil penelitian ini dengan membuktikan adanya pengaruh signifikan dan positif yang diberikan oleh self efficacy terhadap kinerja karyawan.

Ardi et al. (2017) menjelaskan, self efficacy akan memberikan pengaruh pada seseorang dalam membuat pilihan atau keputusan, reaksi emosional, produktivitas, mencari solusi terhadap masalah dan ketekunan dalam bekerja. Hal ini yang kemudian akan memberikan dampak pada hasil kerja seseorang. Chamariyah, (2015) menyebutkan bahwa kemampuan dan kinerja yang telah dicapai sebelumnya merupakan sumber utama terbentuknya self efficacy. Maka dari itu, Nasution et al. (2018) menegaskan bahwa perusahaan perlu mendukung pengembangan karir para karyawannya untuk meningkatkan motivasi kerja sehingga kemudian akan meningkatkan kinerja dan produktivitas mereka.

\section{Pengaruh Motivasi Terhadap Komitmen Karyawan}

Selain pada kinerja karyawan, motivasi kerja juga dapat memberi pengaruh pada Komitmen Karyawan. Penelitian ini membuktikan bahwa motivasi memberikan 
pengaruh secara signifikan dan positif terhadap Komitmen Karyawan perawat RS Hermina Depok (p-value $=0,000 ; \mathrm{CR}=$ 5,948), dengan pengaruh sebesar 0,475. Dengan kata lain, jika motivasi kerja perawat RS Hermina Depok ditingkatkan, maka Komitmen Karyawan pada perawat juga turut meningkat secara signifikan. Penelitian Choong et al. (2011); dan Putri \& Wibawa (2016) menunjukkan hasil yang sejalan, bahwa pengaruh yang diberikan oleh motivasi kerja terhadap Komitmen Karyawan adalah pengaruh yang signifikan dan positif.

Menurut Choong et al. (2011), meningkatkan motivasi kerja kepada karyawan dapat dilakukan, salah satunya dengan memberikan tugas yang menantang dan penuh tanggung jawab namun tetap disesuaikan dengan kemampuan dan bidang mereka, hal ini akan meningkatkan kepuasan kerja dan otomatis akan meningkatkan keterikatan mereka pada perusahaan. Choong et al. (2011) menambahkan, jika seorang karyawan merasa senang dan selalu merasa tertarik dengan tantangan tugas di perusahaannya, karyawan tersebut akan merasa nyaman dan berkomitmen untuk terus bekerja pada perusahaan tersebut.

\section{Pengaruh Self Efficacy Terhadap Komitmen Karyawan}

Komitmen karyawan pada organisasi atau perusahaan juga dipengaruhi oleh self efficacy atau efikasi diri. Hal ini terbukti oleh penelitian ini, bahwa self efficacy mempengaruhi Komitmen Karyawan perawat RS Hermina Depok secara signifikan dan positif ( $\mathrm{p}$-value $=0,000 ; \mathrm{CR}=6,370)$, dengan besar pengaruh 0,508. Hal ini menunjukkan bahwa perawat RS Hermina Depok dengan self efficafy yang semakin meningkat, secara signifikan juga akan meningkatkan komitmennya terhadap rumah sakit. Hasil penelitian Zulkarnain \& Hadiyani (2014) menunjukkan hal yang senada, dimana self efficacy merupakan faktor yang berpengaruh secara signifikan terhadap keterikatan dan komitmen karyawan pada perusahaan.

Sebagaimana disebutkan sebelumnya, bahwa self efficacy terbentuk oleh faktor kemampuan dan hasil kerja pada masa lampau. Sehubungan dengan hasil penelitian ini, apresiasi dalam bentuk kesempatan pengembangan karir, seperti workshop atau seminar, dapat menjadi cara yang efektif untuk mempertahankan karyawan. Hal ini dibenarkan oleh Dayona \& Rinawati (2016); dan Sumadhinata \& Murtisari, (2017) melalui penelitiannya dengan membuktikan adanya pengaruh signifikan dari pengembangan karier yang didukung oleh perusahaan terhadap komitmen karyawan terhadap perusahaan tersebut.

\section{Pengaruh Motivasi, Self Efficacy dan Komitmen Karyawan Terhadap Kinerja Perawat Secara Simultan}

Apabila dianalisis bersama-sama, variabel motivasi, self efficacy maupun Komitmen Karyawan secara bersamaan akan memberikan pengaruh yang signifikan serta positif pada kinerja perawat RS Hermina Depok (p-value $=0,000)$.

Amalia (2018) juga berhasil membuktikan adanya pengaruh motivasi, Komitmen Karyawanonal dan kemampuan secara bersama-sama terhadap hasil kerja perawat, dan penelitian lainnya menambahkan, variabel Komitmen Karyawan merupakan variabel paling dominan dalam memberikan pengaruh terhadap kinerja (Amalia, 2017).

Tabel 2 juga menunjukkan nilai $\mathrm{R}^{2}$ yang diperoleh sebesar 0,817 ; yang artinya variabel kinerja perawat RS Hermina Depok dipengaruhi oleh motivasi, self efficacy, dan Komitmen Karyawan secara simultan sebesar $81,7 \%$, sedangkan sisanya (18,3\%) dipengaruhi oleh variabel lain yang tidak diteliti. Keterlibatan ketiga variabel tersebut cukup besar terhadap kinerja perawat, dengan kata lain, ketiganya merupakan faktor utama 
yang dapat mempengaruhi kinerja perawat RS Hermina Depok.

Sastrohadiwiryo (2012) menerangkan bahwa kinerja merupakan hasil interaksi antara motivasi, komitmen dan kemampuan. Seseorang yang memiliki motivasi tinggi tetapi dengan kemampuan dan/atau komitmen yang rendah, maka kinerja yang akan dihasilkan juga akan rendah. Demikian sebaliknya, seseorang dengan kemampuan yang tinggi namun memiliki motivasi dan/atau komitmen yang rendah, juga akan menghasilkan kinerja yang rendah.

\section{Pengaruh Tidak Langsung}

Analisis pengaruh tidak langsung (mediasi) dilakukan untuk mengetahui kemampuan Komitmen Karyawan dalam memediasi motivasi dan self efficacy dengan kinerja perawat. Pengaruh tidak langsung antara dua variabel ditentukan dengan Path Coefficient dan Sobel Test. Penjumlahan path coefficient pengaruh langsung dengan pengaruh tidak langsung pada hubungan antara dua variabel menentukan besarnya pengaruh variabel bebas terhadap variabel terikat melalui variabel mediasi (Alwi et al., 2019). Selanjutnya, uji hipotesis dilakukan dengan Sobel Test untuk memperoleh pvalue dan T-statistic, hipotesis alternatif atau hipotesis penelitian diterima jika nilai $T$-statistic lebih besar/sama dengan 1,967 atau p-value di bawah 0,05.

Tabel 3

Uji Hipotesis Secara Tidak Langsung

\begin{tabular}{|c|c|c|c|c|c|c|c|}
\hline \multirow{3}{*}{$\begin{array}{c}\text { Hubungan Antar } \\
\text { Konstruk }\end{array}$} & \multirow{3}{*}{$\begin{array}{l}\text { Variabel } \\
\text { Mediasi }\end{array}$} & \multicolumn{2}{|c|}{ Path Coefficient } & \multirow{3}{*}{$\begin{array}{c}\text { Total } \\
\text { Pengaruh }\end{array}$} & \multirow{2}{*}{\multicolumn{2}{|c|}{ Sobel Test }} & \multirow{3}{*}{$\begin{array}{l}\text { Hipotesis } \\
\text { Alternatif }\end{array}$} \\
\hline & & \multirow{2}{*}{$\begin{array}{l}\text { Pengaruh } \\
\text { Langsung }\end{array}$} & \multirow{2}{*}{$\begin{array}{c}\text { Pengaruh } \\
\text { Tidak } \\
\text { Langsung }\end{array}$} & & & & \\
\hline & & & & & T-Statistic & P-Value & \\
\hline $\begin{array}{c}\text { Motivasi - Kinerja } \\
\text { Perawat }\end{array}$ & Komitmen & 0,208 & 0,274 & 0,482 & 3,8026 & 0,001 & Diterima \\
\hline $\begin{array}{c}\text { Self Efficacy - Kinerja } \\
\text { Perawat }\end{array}$ & Karyawan & 0,222 & 0,293 & 0,515 & 3,9056 & 0,000 & Diterima \\
\hline
\end{tabular}

Sumber: Data diolah peneliti (2021)

Pengaruh Motivasi Kerja Terhadap Kinerja Perawat dengan Mediasi Komitmen Karyawan

Berdasarkan Tabel 3, terlihat bahwa kinerja perawat dipengaruhi oleh motivasi kerja secara signifikan yang dimediasi oleh Komitmen Karyawan (p-value $=0,001 ; \mathrm{T}$ statistic $=3,8026)$. Path Coefficient pengaruh tidak langsung yang diperoleh lebih besar daripada Path Coefficient pengaruh langsung yang berarti bahwa Komitmen Karyawan memiliki peranan penting dalam memediasi pengaruh motivasi kerja terhadap kinerja perawat.

Path coefficient total menunjukkan bahwa pengaruh tidak langsung antara dua variabel tersebut dengan mediasi Komitmen Karyawan bersifat positif yaitu sebesar 0,482, artinya peningkatan motivasi kerja akan meningkatkan kinerja perawat melalui peningkatan Komitmen Karyawan. Hasil yang sama diperoleh oleh Ardi et al. (2017); Ghiyats \& Aulia (2020); Polly et al. (2019), dimana ketiga penelitian tersebut membuktikan bahwa Komitmen Karyawan berperan dalam memediasi pengaruh yang diberikan oleh motivasi terhadap kinerja karyawan.

Karyawan menjadikan motivasi sebagai dorongan sehingga karyawan tersebut melakukan upaya terbaik untuk mencapai tujuan perusahaan, dan adanya komitmen mendorong karyawan untuk lebih bertanggung jawabnya dalam menyelesaikan setiap pekerjaan. Maka dari itu, karyawan dengan komitmen kuat terhadap perusahaan 
cenderung akan mengembangkan upaya yang lebih baik pada perusahaan (Coenraad, 2016). Ghiyats \& Aulia (2020) menambahkan, motivasi kerja dapat melahirkan Komitmen Karyawan melalui dorongan bagi karyawan untuk terlibat lebih banyak dan lebih aktif dalam kegiatan atau tugas perusahaan.

\section{Pengaruh Self Efficacy Terhadap Kinerja Perawat dengan Mediasi Komitmen Karyawan}

Pada Tabel 3 juga terlihat bahwa kinerja perawat RS Hermina Depok dipengaruhi secara signifikan oleh self efficacy dan dimediasi oleh Komitmen Karyawan $(\mathrm{p}$-value $=0,000 ; \mathrm{T}$ statistic $=$ 3,9056). Komitmen Karyawan memiliki peranan penting dalam memediasi pengaruh motivasi kerja terhadap kinerja perawat karena Path Coefficient pengaruh tidak langsung lebih besar daripada pengaruh langsung.

Koefisien total mengindikasikan bahwa pengaruh tidak langsung antara dua variabel tersebut dengan mediasi Komitmen Karyawan bersifat positif yaitu sebesar 0,515, artinya peningkatan self efficacy akan meningkatkan kinerja perawat RS Hermina Depok melalui peningkatan Komitmen Karyawan. Penelitian Ardi et al. (2017; Coenraad (2016); Dharma et al. (2019); Ghiyats dan Aulia (2020) memberikan hasil yang senada, dimana self efficacy berpengaruh signifikan dan positif terhadap hasil kerja para karyawan dengan komitmen organisasi sebagai variabel mediasi.

Sebagaimana disebutkan oleh Fajriah dan Darokah (2016), bahwa self efficacy atau efikasi diri mengacu pada keyakinan seseorang terkait kemampuannya dalam melaksanakan tugas, dengan kata lain, jika self efficacy seseorang semakin baik, maka kinerjanya akan semakin baik. Self efficacy meningkatkan kinerja seseorang melalui Komitmen Karyawan yang muncul karena kemampuan yang sesuai dan pengembangan karir yang menunjang keterampilannya. Hal ini dibenarkan oleh Dharma et al. (2019), bahwa jika self efficacy seseorang semakin baik, maka seseorang tersebut akan memberikan hasil kerja terbaik karena adanya komitmen yang kuat, tujuan yang jelas dan kemampuan yang mumpuni.

\section{Kesimpulan}

Berdasarkan data yang diperoleh dari hasil penelitian yang dilakukan maka di peroleh beberapa kesimpulan terdapat pengaruh positif Motivasi dan signifikan antara selfefficacy secara simultan terhadap kinerja perawat di RS Hermina Depok

Terdapat pengaruh signifikan antara komitmen karyawan, motivasi dan self efficacy secara simultan sebesar $81,7 \%$ sangat berpengaruh dengan sikap kepuasan perawat yang dinilai melalui kepuasan terhadap kinerja perawat dan keterlibatan komitmen perawat di RS Hermina Depok

Terdapat pengaruh yang signifikan antara motivasi kerja dan self efficacy secara positif .Perawat yang maknanya adalah dengan adanya program pengembangan karir perawat yang jelas di Rumah Sakit Hermina Depok dapat meningkatkan sikap kerja perawat.

Terdapat pengaruh yang signifikan antara Self Efficacy dengan Komitmen Karyawan yang maknanya adalah kesejahteraan Psikologis yang baik membuat sikap kerja perawat menjadi baik.

Terdapat pengaruh yang signifikan antara Motivasi Perawat dengan Komitmen Karyawan maknanya adalah Motivasi perawat yang tinggi berpengaruh dengan faktor kesejahteraan psikologis perawat yaitu dengan lingkungan kerja yang baik maka sikap kerja perawat menjadi baik.

Terdapat pengaruh yang signifikan antara dengan Self Efficacy dengan Komitmen Karyawan maknanya adalah Program pengembangan karir yang jelas 
Pengaruh Motivasi, Self Efficacy, dan Komitmen Karyawan terhadap Kinerja Perawat di Rumah

Sakit Hermina Depok

dapat memberikan kesejahteraan psikologis yang baik bagi perawat salah satunya adanya hak otonomi perawat yang dihargai dengan adanya pengembangan karir.

\section{BIBLIOGRAFI}

Alwi, M., Ansar, \& Rizak, B. (2019). Pengaruh Budaya Organisasi Dan Komunikasi Terhadap Kinerja Penyuluh Kkbpk Melalui Komitmen Organisasi Dppkb Kabupaten Bantaeng. Journal of Management, 2(3), 1-15. Google Scholar

Amalia, C. D. (2017). Pengaruh Komitmen Organisasi, Kepuasan Kerja Dan Disiplin Kerja Terhadap Kinerja Karyawan (Studi Pada Pt Sarana Bandar Nasional Cabang Banyuwangi). Unvivarsitas Muhammadiyah Jember. Google Scholar

Amalia, R. (2018). Pengaruh Motivasi, Kemampuan Dan Komitmen Organisasional Terhadap Kinerja Perawat Pelaksana Di Rumah Sakit Islam (Rsi) Aisyiyah Malang. Adbis: Jurnal Administrasi Dan Bisnis, 11(2), 124-132. Https://Doi.Org/10.33795/JAdbis.V11i2.23 Google Scholar

Ardi, V. T. P., Astuti, E. S., \& Sulistyo, M. C. W. (2017). Pengaruh Self Efficacy Terhadap Employee Engagement Dan Kinerja Karyawan (Studi Pada Karyawan Pt Telekomunikasi Indonesia Regional V Surabaya). Jurnal Administrasi Bisnis (Jab), 52(1), 163173. Google Scholar

Astuti, R., \& Lesmana, O. P. A. (2018). Pengaruh Motivasi Dan Beban Kerja Terhadap Kinerja Perawat Pada Rumah Sakit Umum Mitra Medika Medan. Jurnal Ilman, 6(2), 42-50. Google Scholar

Azizah, A., \& Gustomo, A. (2015). The Influence Of Employee Engagement To Employee Performance At Pt Telkom Bandung. Journal of Bussiness And
Management, 4(7), 817-829. Google Scholar

Bandura, A. (1997). The Anatomy Of Stages Of Change. American Journal Of Health Promotion: Ajhp, 12(1), 8-10. Google Scholar

Chamariyah. (2015). Pengaruh Self Efficacy, Assertiveness, Dan Self Esteem Terhadap Keinginan Pindah Kerja (Turnover Intentions) Pegawai Pada Bank Jatim Cabang Pamekasan. Jurnal Neo-Bls, 9(1). Google Scholar

Choong, Y.-O., Wong, K.-L., \& Lau, T.-C. (2011). Intrinsic Motivation And Organizational Commitment In The Malaysian Private Higher Education Institutions: An Empirical Study. Journal Of Arts, Science \& Commerce, 2(4), 91-100. Google Scholar

Coenraad, D. P. (2016). Pengaruh Kemampuan, Motivasi Dan Komitmen Terhadap Kinerja Pegawai. Jurnal Ekonomi, Bisnis \& Entrepreneurship, 10(1), 17-24. Google Scholar

Dayona, G., \& Rinawati, N. (2016). Pengaruh Pelatihan Dan Pengembangan Karir Terhadap Employee Engagementdi Pt Andalan Finance Indonesia. Jurnal Indonesia Membangun, 15(2), 39-61. Google Scholar

Dharma, R., Salim, E., \& Harahap, A. S. H. (2019). Pengaruh Locus Of Control Dan Self Efficacyterhadap Kinerja Karyawan Melalui Komitmen Organisasi Sebagai Variabel Intervening Di Pt.Pelindo Ii Padang. Forum Keuangan Dan Bisnis (Fkbi), 7, 333-349. Google Scholar

Fajriah, N., \& Darokah, M. (2016). Pengaruh Efikasi Diri Dan Persepsi Iklim Organisasi Terhadap Kinerja Dengan Employee Engagement Sebagai Variabel Mediator Pada Karyawan Bmt Bif Yogyakarta. Humanitas, 13(1), 3749. Google Scholar 
Ferdinand, R. F. (2008). Validity Of The $\mathrm{Cbcl} / \mathrm{Ysr}$ Dsm-Iv Scales Anxiety Problems And Affective Problems. Journal Of Anxiety Disorders, 22(1), 126-134. Google Scholar

Ghiyats, F., \& Aulia, I. N. (2020). The Effect Of Competence And Motivation Of Employee Performance With Organizational Commitment As Intervening Variables In Pt. Maleo Kreatif Indonesia. International Journal Of Innovative Science And Research Technology, 5(7), 959-966. Google Scholar

Ghozali, I. (2018). Aplikasi Analisis Multivariate Dengan Program Ibm Spss 25. Google Scholar

Gruman, J. A., \& Saks, A. M. (2011). Performance Management And Employee Engagement. Human Resource Management Review, 21(2), 123-136. Google Scholar

Hamali, H. A., \& Saboor, M. (2019). Undiagnosed Hemoglobinopathies: A Potential Threat To The Premarital Screening Program. Pakistan Journal of Medical Sciences, 35(6), 1611. Google Scholar

Ilyas, F. A., \& Nurtjahjanti, H. (2015). Hubungan Antara Efikasi Kerja Dengan Employee Engagement Pada Pegawai Instansi Pemerintahan. Jurnal Empati, 4(2), 76-80. Google Scholar

Indrawan, \& Yaniawati. (2016). Metodologi Penelitian Kuantitatif, Kualitatif, Dan Campuran Untuk Manajemen, Pembangunan, Dan Pendidikan. Refika Aditama. Google Scholar

Jayaweera, T. (2015). Impact Of Work Environmental Factors On Job Performance, Mediating Role Of Work Motivation: A Study Of Hotel Sector In England. International Journal of Business And Management, 10(3), 271. Google Scholar
Kakui, I. M., \& Gachunga, H. (2016). Effects Of Career Development On Employee Performance In The Public Sector: A Case Of National Cereals And Produce Board. Strategic Journals, 3(3), 307324. Google Scholar

Kasmir, S.E., M. . (2016). Analisis Laporan Keuangan. Google Scholar

Kasmir. (2016). Manajemen Sumber Daya Manusia (Teori Dan Praktik) (1st Ed.). Raja Grafindo Persada. Google Scholar

Mahmud, N., Rodriguez, J., \& Nesbit, J. (2010). A Text Message-Based Intervention To Bridge The Healthcare Communication Gap In The Rural Developing World. Technology And Health Care, 18(2), 137-144. Google Scholar

Mardyana, I. K. E., \& Riana, I. G. (2019). Peran Komitmen Organisasional Dalam Memediasi Pengaruh Kepuasan Kerja Terhadap Kinerja Karyawan Krisna Oleh - Oleh. E-Jurnal Manajemen Universitas Udayana, 8(11), 68256846. Google Scholar

Nasution, F. N., Mariatin, E., \& Zahreni, S. (2018). The Influence Of Career Development And Organizational Culture On Employee Performance. International Journal of Scientific Research And Management, 6(1). Google Scholar

Nurfajar, Marzuqi, M. S., \& Rohmayati, N. (2018). Pengaruh Employee Engagement Dan Efikasi Diri Terhadap Kinerja Karyawan Pt Nikomas Gemilang Divisi Pci S5 Serang Banten. Jurnal Pengembangan Wiraswasta, 20(1), 35-46. Google Scholar

Polly, M. D., Laan, R., \& Gesi, B. (2019). Pengaruh Motivasi Intrinsik Dan Ekstrinsik Terhadap Prestasi Kerja Dengan Komitmen Sebagai Variabel Intervening. Jurnal Manajemen, 3(2), 13-27. Google Scholar 
Pengaruh Motivasi, Self Efficacy, dan Komitmen Karyawan terhadap Kinerja Perawat di Rumah Sakit Hermina Depok

Putri, P. E. V., \& Wibawa, I. M. A. (2016). Pengaruh Self-Efficacy Dan Motivasi Kerja Terhadap Kepuasan Kerja Pegawai Bagian Perlengkapan Sekretariat Kabupaten Klungkung. EJurnal Manajemen Unud, 5(11), 73397365. Google Scholar

Riyanto, S., Sutrisno, A., \& Ali, H. (2017). The Impact Of Working Motivation And Working Environment On Employees Performance In Indonesia Stock Exchange. International Review of Management And Marketing, 7(3), 342348. Google Scholar

Robbins, M., Judge, A., \& Maclachlan, I. (2009). Sirna And Innate Immunity. Oligonucleotides, 19(2), 89-102. Google Scholar

Robbins, R. J. (2003). Phenolic Acids In Foods: An Overview Of Analytical Methodology. Journal Of Agricultural And Food Chemistry, 51(10), 28662887. Google Scholar

Salawangi, G. E., Kolibu, F. K., \& Wowor, R. (2018). No Title. Jurnal Kesmas, 7(5), 1-9. Google Scholar

Sastrohadiwiryo, S. (2012). Manajemen Tenaga Kerja Indonesia, Pendekatan Administratif Dan Operasional. Penerbit Bumi Aksara. Google Scholar

Google Scholar Sinambela, L. P. (2012). Kinerja Pegawai: Teori, Pengukuran Dan Implikasi. Yogyakarta: Graha Ilmu. Google Scholar

Sumadhinata, Y. E., \& Murtisari, M. (2017). Pengaruh Pengembangan Karir Terhadap Employee Engagement Pada Karyawan Darat Pt Asdp Indonesia Ferry. Conference On Management And Behavioral Studies. Google Scholar
Sumarni, S., \& Pramuntadi, A. (2019). Pengaruh Komitmen Organisasi Terhadap Kinerja Perawat Di Rs Pk Muhammadiyah Bantul. Jurnal Manajemen Kesehatan Yayasan Rs. Dr. Soetomo, 5(2), 154-164. Google Scholar

Triana, D., \& Widyarto, W. O. (2013). Relevansi Kualilifikasi Kontraktor Bidang Teknik Sipil Terhadap Kualitas Pekerjaan Proyek Konstruksi Di Provinsi Banten. Jurnal Fondasi, 2(2), 182-190. Google Scholar

Wicaksono, M. F. (2017). Implementasi Modul Wifi Nodemcu Esp8266 Untuk Smart Home. Komputika: Jurnal Sistem Komputer, 6(1). Google Scholar

Zainaro, M. A., Isnainy, U. C. A. S., Furqoni, P. D., \& Wati, K. (2017). Pengaruh Motivasi Kerja Terhadap Kinerja Perawat Pelaksana Di Ruang Rawat Inap Rumah Sakit Umum Daerah Alimuddin Umar Kabupaten Lampung Barat Tahun 2017. Holistik Jurnal Kesehatan, 11(4), 209-215. Google Scholar

Zulkarnain, -, \& Hadiyani, S. (2014). Peranan Komitmen Organisasi Dan Employee Engagement Terhadap Kesiapan Karyawan Untuk Berubah. Jurnal Psikologi, 41(1), 17-33. Google Scholar 
Nurianna Harianja, Rokiah Kusumapraja, CSP Wekadigunawan

\section{Copyright holder:}

Nurianna Harianja, Rokiah Kusumapraja, CSP Wekadigunawan (2022)

First publication right:

Jurnal Health Sains

This article is licensed under:

(c) () () 